\title{
Optimal Surface Depth Study of Photovoltaic Modules with Immersion Cooling
}

\author{
Li Lei, Xiao Lixian, He Yongtai, Zhao Zhijun, Hong Yufu, and Gao Ke \\ School of Physics \& Electronic Science, Chu Xiong Normal University, Chu Xiong, China, 675000
}

Keywords: photovoltaic modules; efficiency; temperature; optimum water film depth; cooling

\begin{abstract}
The corresponding thickness of the water film on the surface of the photovoltaic module can effectively absorb the heat generated by the work of the component, and can effectively improve the working efficiency of the component. In this paper, by using the solar module analyzer (PROVA), the electrical parameters (V, I, P) of the single crystal silicon photovoltaic module are tested. The output characteristics of the photovoltaic module on the surface with Immersion Cooling are explored, and the output characteristics of the PV module are compared with the best water temperature of the best water film. The results show that when the photovoltaic module is placed horizontally, the output power of the water film thickness between $0.24 \mathrm{~cm}$ and $0.3 \mathrm{~cm}$ is the best. Under the same irradiation condition, the output power of the same piece of PV module is the best when the water film temperature of the component surface is 25 degrees centigrade. The research is of great significance to the design and construction of photovoltaic power stations in the future.
\end{abstract}

\section{Introduction}

With the continuous maturity of solar photovoltaic power generation technology, the conversion efficiency of solar cells has been greatly improved, but the efficiency of solar cells still has not reached the expected results. One of the main reasons is that the sun irradiation to the surface of the component is not completely converted to electrical energy, but rather the heat dissipation and consumption of the solar cell, and the more serious is that the conversion efficiency of the solar cell will decrease with the increase of the temperature of the solar cell. In order to reduce the working temperature of solar cells and improve the photoelectric conversion efficiency, it is necessary to adopt effective cooling measures for PV modules. Installing special heat sink or heat dissipation channel $[1,2]$ behind the component can not only play a role in cooling the solar cell, but also make use of the heat of the back of the component. Liquid water is the most common cooling worker in the selection of refrigerants. Liquid water can be used on the back of the battery and can also be used in solar power. On the front side of the pool, the first photovoltaic component immersed in liquid working fluid was a patent technology [7] in the US in 2006. With the research of liquid cooled photovoltaic modules, there are more and more patents and papers appearing in $[8,9,10,11]$. Due to its uniform heat dissipation, solar cells immersed in liquid can reduce the hot spot effect of components. In 2008, Yi Ping Wang[2] investigated the performance of silicon solar cells operated. He University of Shanghai for Science and Technology, Chen Jianbo[4] studied on the surface of the component to form a uniform layer of water film to reduce the temperature of the component, and improve the efficiency of the component. The advantage of this method is that the heat can be taken away by the flow water when the component works, but the water on the surface of the component is flowing, and the optimum water film thickness In 2017 on the surface of the PV component can not be accurately calculated. Li Lei reveals the electrical characteristics of the photovoltaic module immersed in $0 \mathrm{~cm} 15 \mathrm{~cm}$ underwater.

In this paper, a theoretical model of submerged cooling photovoltaic module is established, and the influence of water film depth and water temperature on the performance of PV module is explored, and the optimum water film depth is revealed. At the same time, a test platform for the soaked cooling photovoltaic module is set up, and the theoretical model is verified. In order to better solve this shortcoming, the PV module is placed horizontally and measured with a horizontal tester, then the effective area of the PV module is calculated, and then the amount of water required for the different water film is calculated. Then the weighing water is dumped on the surface of the 
photovoltaic module, so the photovoltaic module is cooled down so that it can be more effective. The best depth of the water film on the surface of the PV module is accurately captured [1].

\section{Experimental Equipment and Process}

This experiment uses the solar module analyzer (PROVA) test instrument to collect the information of the working time of the photovoltaic module (the IV curve of the photovoltaic module) through the outdoor test, and uses the energy efficiency test system of renewable energy to detect the surface temperature of the component, the temperature of the component back and the ambient temperature. In order to ensure the accuracy of the test, in the process of testing, the whole process is to measure the thickness of the water film on the surface of the photovoltaic module by the same piece of photovoltaic module. The whole process is to place the component in the south direction. After the component is immersed in the $2 \mathrm{~cm}$ water film, the water is then reduced by $0.2 \mathrm{~cm}$ in turn, and the IV characteristic curve of the photovoltaic module is tested.

Because the thickness of the water film below $0.1 \mathrm{~cm}$ is too thin and the saturation of the glass and water of the photovoltaic module is not good, the surface of the $0 \mathrm{~cm}<$ film thickness can not be fully covered in the range of $<0.1 \mathrm{~cm}$, which can not be measured, and the thickness range of the final test water film is $0.12 \mathrm{~cm} 0.5 \mathrm{~cm}$.

Table 1 Electrical parameters of photovoltaic modules

\begin{tabular}{cccc}
\hline PV & $\begin{array}{c}\text { Monocrystalline } \\
\text { silicon PV 10W }\end{array}$ & Working current & $0.56 \mathrm{~A}$ \\
\hline maximum power & $10 \mathrm{~W}$ & $\begin{array}{c}\text { Open circuit } \\
\text { voltage } \\
\text { Short circuit } \\
\text { current }\end{array}$ & $21.6 \mathrm{~V}$ \\
Working voltage & $18.0 \mathrm{~V}$ & $0.62 \mathrm{~A}$ \\
\hline
\end{tabular}

Table 2 Instrument parameters

\begin{tabular}{|c|c|c|c|}
\hline $\begin{array}{c}\text { Serial } \\
\text { number }\end{array}$ & Device name & accuracy & Range \\
\hline 1 & $\begin{array}{c}\text { Solar Module } \\
\text { Analyzer }\end{array}$ & $+/-1 \%$ & $0-1999 \mathrm{~W} / \mathrm{m}^{2}$ \\
\hline 2 & solar irradiation meter & $< \pm 2 \%$ & $0 \sim 1999 \mathrm{~W} / \mathrm{m}^{2}$ \\
\hline 3 & $\begin{array}{c}\text { TMC-2D renewable } \\
\text { energy efficiency } \\
\text { evaluation system }\end{array}$ & $\begin{array}{c} \pm 5 \% \mathrm{~W} / \mathrm{m}^{2} \\
\pm 0.1^{\circ} \mathrm{C}\end{array}$ & $\begin{array}{l}0 \sim 2000 \mathrm{~W} / \mathrm{m}^{2} \\
-40^{\circ} \mathrm{C} \sim 300^{\circ} \mathrm{C}\end{array}$ \\
\hline
\end{tabular}

\section{Experimental Analysis}

On the day of the test, the weather turned cloudy and cloudy, and the average wind speed was about $1.7 \mathrm{~m} / \mathrm{s}$. The solar radiation of the day was as shown in Fig. 1. The maximum irradiation on the test day appeared at 13:51, and the irradiation value was $961 \mathrm{~W} / \mathrm{m}^{2}$.

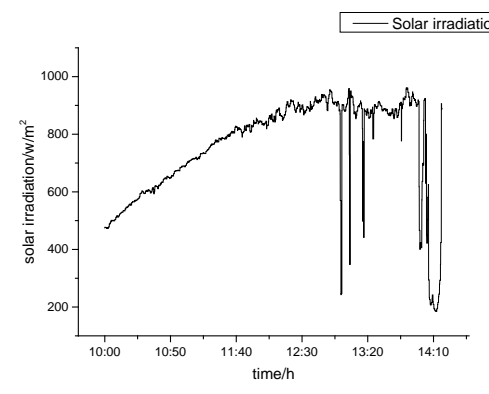

Fig.1 Solar radiation of test

By arranging the data of the monocrystalline silicon photovoltaic modules tested by the solar 
module tester, the IV characteristic curves of the components with different water film depths of $0.12 \mathrm{~cm} \sim 0.5 \mathrm{~cm}$ were drawn and compared. Fig. 2 shows Relationship between different water film thicknesses on the maximum power, maximum voltage, maximum current and fill factor of monocrystalline silicon photovoltaic modules. Figure 2-a is the relationship between the maximum power of photovoltaic modules and water film thickness, Figure 2-b is the maximum voltage and water film of photovoltaic modules After the relationship curve, Figure 2-c is the relationship between the maximum current of the PV module and the water film thickness, and Figure 2-d is the relationship between the PV module fill factor and the water film thickness.

It can be seen from Fig. 2-a that the power of the photovoltaic module is significantly increased during the process of increasing the thickness of the water film to $0.26 \mathrm{~cm}$, especially in the power modules of $0.24 \mathrm{~cm}$ to $0.26 \mathrm{~cm}$. After $0.26 \mathrm{~cm}$, as the thickness of the water film increases, the power of the photovoltaic module begins to decrease, especially at a decrease of $0.32 \mathrm{~cm}$ to $0.36 \mathrm{~cm}$. It can be seen from the figure that the thickness of the water film greater than $0.26 \mathrm{~cm}$ is more effective for cooling the photovoltaic module. The reason for this is that the water film thickness is around $0 \sim 0.24 \mathrm{~cm}$, and the water film on the surface of the PV module is too thin. Due to the high temperature $\left(50^{\circ} \mathrm{C}-70^{\circ} \mathrm{C}\right)$ generated during the operation of the module, the water film on the surface of the module is short. The heat generated by the component is heated and warmed up, and cannot be cooled to the component. When the surface water film thickness of the photovoltaic module is greater than $0.3 \mathrm{~cm}$, the water film is too thick, and the water film cools down the photovoltaic component, but the water The absorption of solar radiation by the membrane dominates, and the power of the solar cell begins to decline due to the weakening of the radiation. The thickness of the water film is about $0.26 \mathrm{~cm}$, the maximum power of the photovoltaic module is $9.23 \mathrm{~W}$, the average power value is $8.58 \mathrm{~W}$, and the power value of the waterless photovoltaic module is the smallest, $7.57 \mathrm{~W}$. It is obvious that the power of the photovoltaic module is affected by the water film. And the thickness of the water film changes slightly, and the output of the photovoltaic module is more obvious.

It can be seen from Fig. 2-b that the maximum voltage of the PV module is $0.3 \mathrm{~cm}$ at the water film thickness, the maximum voltage value is $21.83 \mathrm{~V}$, and the average voltage value is $21.63 \mathrm{~V}$ when the water film thickness is changed from 0 to $0.5 \mathrm{~cm}$. The photovoltaic module has the lowest voltage value of $20.72 \mathrm{~V}$, which indicates that the surface water film of the component has a relatively large influence on the component voltage, and the influence is relatively stable. When the water film is on the surface of the photovoltaic module, the voltage of the photovoltaic module is above $21.4 \mathrm{~V}$, and the voltage is obviously improved compared with the photovoltaic module of the waterless film. However, there is a water film on the surface of the photovoltaic module. The voltage is obviously divided into two sections. The water film thickness is less than $0.3 \mathrm{~cm}$. The voltage value is above $21.6 \mathrm{~V}$. The voltage tends to be stable. After the water film thickness is greater than $0.3 \mathrm{~cm}$, the voltage is reduced. A step is lowered, and the voltage of the photovoltaic module without a film is small, which is mainly affected by the high temperature generated by the component during operation, and the open circuit voltage of the solar cell decreases as the temperature increases. First, because the water film on the surface of the component is too deep, most of the solar radiation is reflected and absorbed by the water, which causes the water temperature to increase and the temperature of the component rises. Second, because the water film is too thick, the surface of the component is directly received. The amount of solar radiation is reduced, which eventually leads to a voltage drop.

From Fig. 2-d, the fill factor curve of the PV module fluctuates between 0.68 and 0.74 , and the standard deviation of the fill factor is 0.02 , the average value is 0.71 , and the change of the fill factor deviates from the standard deviation, because the PV module water Uniform coverage of the film does not affect the series-parallel resistance of the photovoltaic module, and thus does not affect the fill factor of the photovoltaic module.

From the above four figures, the power, current and voltage of the component will be affected by the water film thickness on the surface of the component. The optimal thickness of the water film is around $0.26-0.3 \mathrm{~cm}$, when the water film thickness is less than the optimal water film. The water 
film is too thin, and the water film is heated by the assembly to have an effective cooling effect. When the water film thickness is larger than the optimal water film, the solar film surface of the photovoltaic module is affected by the excessive thickness of the water film, which leads to the reduction of the power, voltage and current of the photovoltaic module. The fill factor is mainly related to the series-parallel resistance of the component. The uniform water film covers and cannot change the series-parallel resistance of the component, so the fill factor is independent of the water film thickness of the component surface.

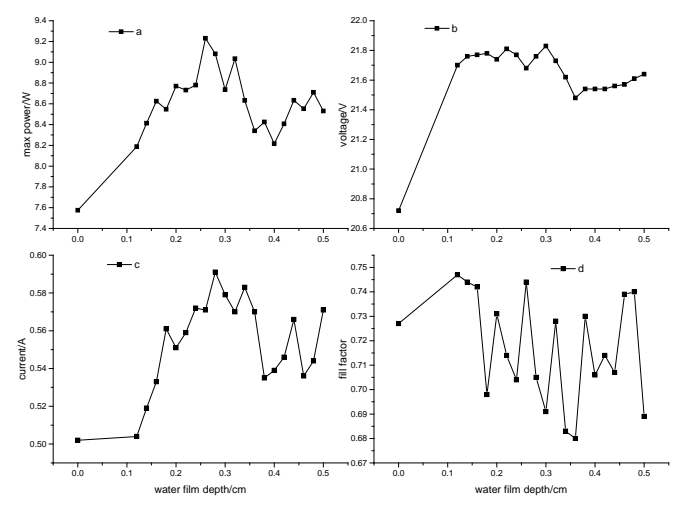

Fig. 2 Relationship between water film depth and PV module power, voltage, current and fill factor

At the optimum water film thickness, the relationship between the water temperature and the output characteristics of PV modules is tested. The temperature range is $22 \sim 45 \mathrm{C}$.

When the optimum water film thickness is, the relation between the water temperature and the maximum power of the component, the power value at the low temperature stage are all greater than the power value at the high temperature stage, which indicates that the higher the temperature of the component, the lower the power of the photovoltaic module. The maximum power point is 25 degrees at the water temperature, the maximum power is $7.90 \mathrm{~W}$, the water temperature is 45 degrees, the component power is $6.86 \mathrm{~W}$, and the average power is $7.38 \mathrm{~W}$. From 22 to 25, the power value increases, and the power value decreases from 25 to 45 . When the PV module is in the best water film thickness, the water temperature is related to the component voltage. The voltage value at the low temperature section is higher than the voltage of the high temperature section. This indicates that the voltage value of the photovoltaic module is also greatly influenced by the temperature. The maximum voltage is at the water temperature of 25 degrees $\mathrm{C}$, the maximum voltage is $21.79 \mathrm{~V}$, the minimum voltage is at the water temperature of $45 \mathrm{C}$, and its value is $20.29 \mathrm{~V}$. The average voltage is $21.19 \mathrm{~V}$ and the voltage is stable at $22 \mathrm{C}$ to $25 \mathrm{C}$. The voltage will decrease with the increase of temperature from 25 to $45 \mathrm{C}$ with the increase of temperature. For the single solar cell, the open circuit voltage of the single solar cell is reduced by $210 \mathrm{MV} 212 \mathrm{mv}$ when the component is raised by 1 degrees $\mathrm{C}$; so when the temperature of the component is from the component, The voltage will obviously decrease when the temperature rises to 45 degrees 25 .

The PV module is in the same water film thickness, water temperature and component current, the maximum current value is at $25 \mathrm{C}$, the value is $0.464 \mathrm{~A}$, the minimum value at water temperature is $40 \mathrm{C}$, the value is $0.438 \mathrm{~A}$, and the maximum and the minimum difference is $0.026 \mathrm{~A}[3]$.

The filling factor of the PV module at the same water film thickness and different water temperature, from the whole curve, the curve is changed in the range of 0.768 to 0.788 , the maximum value difference is 0.02 , the average value of the filling factor is 0.77612 , the variance of the filling factor of the PV module is 0.007 , the water film thickness of the component is fixed, and it is all the same. Uniform, the change is only the temperature of the component, and the temperature has no effect on the series and parallel resistance of the component, so the filling factor of the PV module is not affected by the temperature of the photovoltaic group. The power, current and voltage of the photovoltaic module are affected by the high temperature produced by the photovoltaic module. The higher the temperature is, the power and the voltage of the PV module 
will be reduced, and the current of the component will rise with the increase of temperature, but the current of the component is small, and there is no large voltage change, so the temperature of the component is raised. The power of components at high time is reduced, and the efficiency of components is also decreasing.

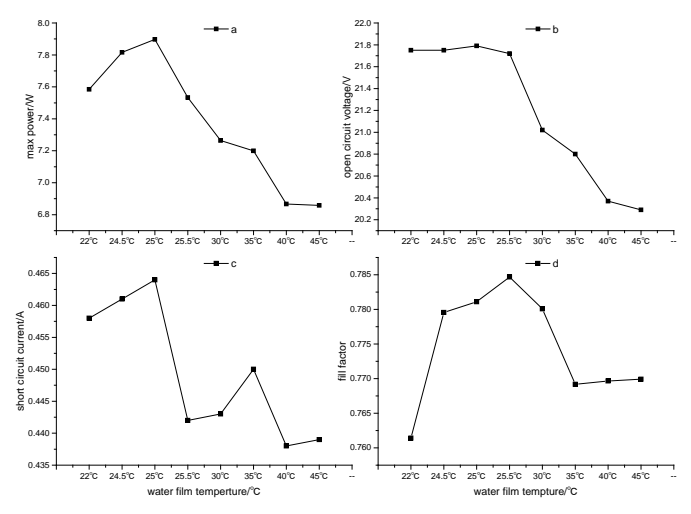

Fig. 3 Relationship between water temperature and PV module power, open circuit voltage, short circuit current and fill factor.

Figure 3-d shows the fill factor of the PV module at the same water film thickness and different water temperature. From the curve as a whole, the curve changes from 0.768 to 0.788 . The difference between the two values is 0.02 , and the average value of the fill factor is 0.77612 , the variance of the filling factor of the photovoltaic module is 0.007 , the water film thickness of the component is fixed, and it is uniform, only the temperature of the component is changed, and the temperature has no influence on the series-parallel resistance of the component, so the photovoltaic component The fill factor does not affect the temperature of the PV group.

Based on the curve analysis of the above four graphs, the power, current and voltage of the PV modules will be affected by the high temperature generated by the PV modules. The higher the temperature, the lower the power and voltage of the PV modules, and the current of the components will follow the temperature. It rises and rises, but the current change of the component is relatively small, and there is no large voltage change, so the power of the component is reduced when the temperature of the component is increased, and the efficiency of the component is also reduced.

Table 3 compares the maximum power, open circuit voltage, short circuit current, and fill factor for the optimum water film depth and waterless film on the surface of the PV module. It can be seen from the table that the maximum power, open circuit voltage and short circuit current under the optimal water film depth are greater than the maximum power, open circuit voltage and short circuit current of the PV module without film water.

The maximum power value of the PV module under the optimal water film depth in Table 3 is $21.9 \%$ of the maximum power of the water film; the open circuit voltage of the PV module under the optimal water film depth exceeds the open circuit voltage of $4.6 \%$ when it is no water; The short-circuit current of the PV module under the optimal water film depth exceeds the short-circuit current of $13.7 \%$ when it is no water. Explain that the optimal water film depth on the surface of the PV module can play a more significant role in the operation of the component. It can effectively absorb the high temperature generated by the component and cool the component, thereby improving the efficiency of the photovoltaic module.

Table 3 Comparison of the best water film depth and water free

\begin{tabular}{ccccc}
\hline $\begin{array}{c}\text { Water film } \\
\text { detpht/cm }\end{array}$ & $\begin{array}{c}\text { Max } \\
\text { power/W }\end{array}$ & voltage/V & current/A & Fill factor \\
\hline 0 & 7.575 & 20.72 & 0.502 & 0.727 \\
0.26 & 9.231 & 21.68 & 0.571 & 0.744 \\
\hline
\end{tabular}




\section{Conclusions}

In order to better analyze the influence of different film thickness on the electrical parameters (I, $\mathrm{V}, \mathrm{P}$ ) of the polysilicon photovoltaic module, 21 different water film thickness of the same photovoltaic module were tested in the experiment. The experiment also tested 8 different water temperatures of the PV module. Finally, the experimental results are analyzed and studied in detail, and the following conclusions are drawn:

1. The efficiency of the time volt component with the thickness of the water film between $0.24 \mathrm{~cm}$ and $0.3 \mathrm{~cm}$ on the surface of the photovoltaic module is the best. Compared with the surface of the photovoltaic module, the efficiency of the photovoltaic module is much higher than that of the photovoltaic module. At the same time, the power value, the electric pressure value and the current value of the photovoltaic module are all subject to the photovoltaic group. The influence of the thickness of the water film on the surface of the piece. The surface water film on the surface of the photovoltaic module is too thin, although the absorption of the solar radiation is not much, but the thin film will lead to the uniformity of the surface distribution of the photovoltaic components, and the temperature of the water will rise rapidly because of the high temperature of the component, and can not play the effect of cooling. When the water film on the surface of the photovoltaic module is too thick, the cooling effect is obvious, but more solar radiation will be absorbed, so that the photovoltaic module can not absorb the solar radiation, which will also affect the efficiency of the photovoltaic module.

2. Under the same sun irradiation, the surface water film thickness of the photovoltaic module is fixed to $0.3 \mathrm{~cm}$, changing the water temperature on the surface of the photovoltaic module. The efficiency of the PV module below $25 \mathrm{C}$ will also decrease obviously. The difference between the efficiency of the PV module at the temperature of $25 \mathrm{C}$ is $0.35 \%$, and the temperature of the PV module is also affected by the water temperature when the water temperature is over 25 . The efficiency is reduced by contrast, and the difference is $1.35 \%$ when the water temperature is 25 degrees. It is shown that the efficiency of the photovoltaic module is obviously affected by the temperature, and the efficiency of the PV module will be greatly reduced at 25 degrees centigrade.

3. In the test, the water film thickness on the surface of the photovoltaic module is tested by the optimum value of $0.3 \mathrm{~cm}$. The water of $20 \mathrm{C}$ or $70 \mathrm{C}$ falls on the surface of the component. After 10 minutes, the water temperature will be maintained at $30+5$ centigrade on the surface of the component, and the temperature of the PV module without water film will rise to more than 50 degrees centigrade.

\section{Acknowledgements}

This research was financially supported by Yunnan Applied Basic Research Projects (2017FD151), National Innovation and Entrepreneurship Training Program for College Students in 2017(201711391001).

\section{References}

[1] K. Tanaka. Solar energy converter using a solar cell in a shallow liquid layer, Patent US6583349B2, 2003.

[2] G. Carcangiu, M. Sardo, I. Carcangiu, R. Sardo, Photovoltaic panel and solar panel unit made using photovoltaic panels of the same sort, Patent US2008/0092876A1, 2008.

[3] A.H. Ignacio, S.P. Gabriel, D.D. Cesar y, V.P. Marta. Photovoltaic concentrator with a high efficiency immersed into a reflective optical dielectric liquid, Patent 2302656, 2008,

[4] DENG Ruru, HE Yingqing, QIN Yan, etc. Pure water absorption coefficient measurement after eliminating the impact of suspended substance in spectrum from 400nm to $900 \mathrm{~nm}$. Journal of Remote Sensing [J]. 1007-4619 (2012) 01-176-18. 